\title{
CRÍTICA LITERÁRIA FEMINISTA: REVISITANDO AS ORIGENS
}

\section{FEMINIST LITERARY CRITICISM: REVISITING ORIGINS}

\author{
Anselmo Peres Alós \\ Universidade Federal de Santa Maria, UFSM, Santa Maria, RS, Brasil \\ Bárbara Loureiro Andreta \\ Universidade Federal de Santa Maria, UFSM, Santa Maria, RS, Brasil
}

\begin{abstract}
Resumo: O presente artigo tem o objetivo de revisitar as origens da crítica literária feminista. Nesse sentido, ao retomar as três ondas do feminismo, recuperam-se os principais conceitos que embasaram o pensamento feminista em cada momento histórico, bem como as principais mulheres que ocuparam grande importância para o imaginário do feminismo ao longo de sua história. Essa retomada histórica evidencia o conceito interdisciplinar da crítica literária feminista, uma vez que esta náo admite uma leitura de texto desvinculada de sua exterioridade e de sua historicidade.
\end{abstract}

Palavras-chave: Crítica literária feminista; Origens. Três ondas.

Abstract: This article aims at revisiting the feminist literary criticism origins. In this sense, when these three feminist strands are revisited, the main concepts that gave basis to the feminist thinking, in each historical moment, are brought back. Besides this, the main women who are of great importance for the feminist imaginary along the history of the movement are also restudied. This historical retake highlights the interdisciplinary concept of the feminist literary criticism since it does not admit the unlinked reading of a text. The exteriority and historical context have to be always considered.

Keywords: Feminist literary criticism; Origins. Three literary strands.

The experience of writing in class in the presence of others seems to evoke deeper reflection and sharing than either writing at hope and sharing in class or simply sharing in class. It is easier for those of us who are insecure about our writing to write in the presence of other women who are also writing. The limited time for writing seems to encourage us to dive immediately into our depths. I always speak of the importance of writing freely, without selfcensorship or concern for grammar, spelling, or sentence structure. Each of us can edit out anything too private or painful when we share in the small group. However, I urge each woman to read directly from her journal in the small group. It seems to be easier for many of us to share deep feelings, insights, fears if we read what we have written rather than speak about it. Also, when we read from our journals, we often get positive feedback about the power of our writing and about our abilities to name our experiences in a way that is

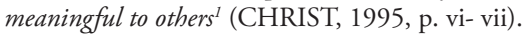

1 “A experiência de escrever em sala de aula em presença d@soutr@s parece evocar 


\section{Preâmbulo: as três ondas}

É recorrente ouvir-se falar, nas primeiras aproximaçóes à teoria feminista, das três ondas do feminismo. A grande responsável por esse olhar que, em última análise, consolida uma visão que divide a história do movimento feminista - entendido tanto política quanto teoricamente - foi a jornalista Martha Weinman Lear, que, em 10 de março de 1968, publicou, no The New York Times Magazine, um artigo intitulado The Second Feminist Wave. Nesse texto, Lear (1968) instaura a noção de "segunda onda" para descrever o próprio contexto que estava vivendo; consequentemente, todo o feminismo anterior foi subsumido na categoria "primeira onda". Tal metáfora tem se mostrado bastante frutífera - didática até - para que se possa compreender a evoluçáo histórica do movimento internacional de mulheres, da teoria feminista e das reivindicaçóes e lutas sociais pelos direitos das mulheres.

Posteriormente, na década de 1990, as profundas reformulaçôes que surgiram do diálogo e da reformulaçáo das agendas política e teórica do feminismo - em especial do feminismo institucionalizado nos Departamentos de Humanidades das grandes universidades estadunidenses e europeias, passou-se a utilizar o termo "terceira onda" para dar conta desse feminismo que hoje pode ser identificado como pós-humanista, pós-estruturalista, construcionista, ou mesmo pós-moderno (por ora, deixemos de lado as implicaçóes teóricas do uso de cada um desses termos, suas afinidades e contendas políticas e respectivas consequências). Pareceme importante salientar, ainda, para além dessa tríplice categorização, a existência do que poderia ser chamado de um protofeminismo, ou feminismo avant lalettre, para dar conta de figuras históricas de suma importância para o imaginário político do feminismo, mas que não chegam a formar um corpus

simultaneamente profunda reflexão e compartilhamento, mais do que escrever em casa e compartilhar em classe, ou simplesmente compartilhar/discutir em classe. É mais fácil para aquel@s de nós que estâo insegur@s da própria escrita na presença de outr@s que estão também escrevendo. O tempo limitado para a escrita parece encorajar-nos a mergulhar imediatamente em nossas profundezas. Sempre falo da importância de escrever livremente, sem autocensura ou preocupaçôes com gramática, ortografia ou estrutura sintática. Cada um de nós pode também editar, quando compartilhamos com o pequeno grupo. Contudo, chamo a atençáo de cada um/a para ler diretamente de suas anotaçôes. Parece mais fácil para muit@s de nós compartilhar sentimentos profundos, novas ideias e medos se lemos aquilo que acabamos de escrever do que quando nos expressamos oralmente, em uma discussáo. Quando lemos a partir de nossas anotaçōes pessoais, frequentemente temos um retorno acerca do poder de nossa escrita e de nossas habilidades de dar nome às nossas próprias experiências de uma forma efetivamente significativa para @s outr@s” [tradução nossa]. 
de textos e discursos, documentos artísticos ou científicos com a mesma homogeneidade que ocorre quando pensamos nas três ondas feministas. Em função de nosso próprio trabalho intelectual e da atenção que detivemos na obra literária das escritoras brasileiras do século XIX, parece-nos bastante pertinente propor uma cisáo - ainda que pareça um tanto arbitrária - entre um protofeminismo e o feminismo da primeira onda. Parece-nos produtivo reservar o termo "primeira onda" para o feminismo que se desenvolveu a partir do século XIX e usar a categoria protofeminismo para designar o pensamento anterior ao século XIX. Dessa maneira, torna-se possível colocar a produção literária do século XIX - momento em que as mulheres passam sistematicamente a se apropriar da posição de autoras e de produtoras e capital simbólico no mundo ocidental - em uma posiçáo de simultaneidade com o pensamento feminista que lhe é contemporâneo.

O protofeminismo abarcaria, então, um conjunto de obras, ideias e personagens históricas que foram resgatados pelo feminismo como precursores, mas que não chegam a formar um corpo sistemático de textos ou um modelo teórico e coerente de pensamento. Podemos situar, nesse momento, o trabalho de Christine de Pizan (1405), La cité des dames (traduzido e publicado no Brasil apenas em 2012); a vida de Joana D’Arc (1412-1431) e a mística que se produziu a partir do seu protagonismo na História; Margareth Cavendish (1661-1717) e seu The convent of pleasure; Mary Wolstonecraft (1759-1797) e o célebre Vindications of the right sof the women; Catherine Macaulay (1731-1791), e suas Letters on education with observations on religions and metaphysical subjects (1790).

No bojo da primeira onda feminista, cujos efeitos mais expressivos fizeram-se notar especialmente no final do século XIX e inícios do século $\mathrm{XX}$, as principais reivindicaçóes são o fim dos casamentos forçados, o direito ao voto feminino e o acesso à educaçáo formal. Frequentemente, se aponta como um dos pontos críticos do feminismo de primeira onda suas características elitistas e liberais, que o converteriam em um movimento social branco e burguês, pouco ou nada atento às questóes de raça e classe. Importa salientar, entretanto, que no contexto estadunidense há uma longa história de coalizão política entre interesses feministas e a luta pela abolição da escravatura e pela ampliação dos direitos civis.

O renascimento do debate feminista e a emersão da chamada segunda onda ocorreram na esteira da revolução sexual, motivada, principalmente, pelo impacto do advento da pílula anticoncepcional, aprovada como método contraceptivo em 1960, nos Estados Unidos. Isso permitiu às mulheres uma autonomia no controle da natalidade - e, consequentemente, nas maneiras 
pelas quais as mulheres administravam os usos políticos de seus corpos nunca antes imaginada. Esse feminismo renovado emergiu após a Segunda Guerra Mundial e teve um diálogo intenso com o movimento pelos direitos civis nos Estados Unidos, o movimento hippie e o movimento sindical dos trabalhares. Isto é, um feminismo que começou a ficar mais atento (e menos ingênuo) às questóes de raça, classe e sexualidade. Como resultado de acalorados debates na esfera pública, apareceram, no mercado editorial, livros fundamentais ainda hoje para o pensamento feminista, como os de Simone de Beauvoir (em especial os dois volumes de $\mathbf{O}$ segundo sexo), de Betty Friedan (A mística feminina, 1963 - traduzido para o português em 1971); Carol Hanisch (responsável por formular, pela primeira vez, o slogan "o pessoal é político", no artigo The personal is political, de 1969), Kate Millet (Sexual politics, de 1969, escrito originalmente como tese de doutoramento em Literatura Comparada) e Nancy Chodorow (Psicanálise da maternidade - publicado pela primeira vez, em inglês, em 1978, com o título The reproduction of mothering).

Ao longo do final da década de 1980 e no início da década de 1990, a preocupação com o refinamento do instrumental teórico do feminismo nas mais diversas searas disciplinares, e os diálogos, embates e confrontos que o pensamento feminista estabeleceu com o pós-estruturalismo, as teorias da pós-modernidade e o advento da virada teórica na academia possibilitou uma reformulação de inúmeras questóes marginais que não foram suficientemente discutidas pela "segunda onda". Podemos pensar nas propostas delineadas na intersecçáo de gênero e raça propostas por Barbara Smith (The thuth that never hurts: writings on race, gender and freedom, 1998) e bellhooks (Teachin to transgress, 1994), o feminismo pós-moderno de Jane Flax (Thinking fragments, 1990), ou o trabalho de Teresa de Lauretis (Technologies of gender, 1987)e de Judith Butler (Gender trouble, 1990; Bodies that matter, 1993), que desaguariam mais tarde na formulação de uma proposta teórica associada às perspectivas queer.

Finalmente, cabe fazer uma breve discussão do termo pós-feminismo. O pós-feminismo trata-se, na verdade, de uma tentativa de estancar o avanço - tanto teórico quanto político - das diferentes correntes do pensamento feminista a partir da falsa ideia de que o feminismo já fez tudo o que podia pelas mulheres em termos políticos, e agora elas se encontrariam "liberadas" e prontas para fazer o que quiserem, tomando as rédeas de suas próprias vidas e fazendo suas próprias escolhas, em um mundo livre de opressóes motivadas por sexo/gênero. $\mathrm{O}$ termo pós-feminismo emergiu na década de 1980, na imprensa estadunidense, de maneira a rechaçar o pensamento feminista, criticando lacunas e ineficácias dos feminismos da segunda e da 
terceira onda. Embora possa ser considerado como uma alternativa teórica - que produziu interessantes insights a partir do confronto do pensamento feminista e da cultura popular de apelo massivo - e uma possibilidade de revisão para as lacunas do pensamento feminista anterior, o pós-feminismo não raro reitera posturas neoliberais e conservadoras, pautada em categorias de análise um tanto problemáticas, tais como o livre-arbítrio radical, a meritocracia e o individualismo.

É curioso observar que, nessa demonização do feminismo como o responsável pelas frustraçóes das mulheres, a cultura popular, o marketing e a publicidade operam o mesmo movimento de captura da subjetividade feminina que havia sido descrito por Betty Friedan (1963) em The feminine mystique, quando a autora tenta compreender a frustração das mulheres da década de 1960. De acordo com Angela McRobbie (2004, p. 255-256, tradução nossa), as ambivalências do pós-feminismo podem ser compreendidas a partir da "coexistência de valores neoconservadores em relação ao gênero, à sexualidade e à vida familiar [...] com os processos de liberação relativos à escolha e à diversidade nas relações domésticas, sexuais e parentais"2.

Personagens supostamente liberadas e independentes, tais como Bridget Jones e Carrie Bradshaw, oriundas da ficção popular e depois celebrizadas por produçôes para o cinema e a televisão, mostram-nos a falácia do "pós-feminismo": elas têm carreiras profissionais, uma vida sexual ativa e independente, roupas da moda, bom-gosto, inteligência e humor. Mas, ao fim e ao cabo, estáo desesperadas em uma busca irracional pelo amor, que continua ocupando o lugar de telos existencial na vida feminina. Em Backlash: the unde clared war against American women, Susan Faludi (1991) identifica o pós-feminismo como um movimento que redefiniu o feminismo em seus próprios termos, colocando o pensamento feminista como a fonte de muitos dos problemas que estariam atormentando as mulheres contemporâneas. Cabe ressaltar que o pós-feminismo, da mesma maneira que a crítica ao "politicamente correto", é visto por Faludi como uma estratégia da imprensa conservadora estadunidense para implodir com os avanços do feminismo no campo das discussóes acadêmicas e sociais.

\footnotetext{
2 "[...] co-existence of neo-conservative values in relation to gender, sexuality and family life [...] with processes of liberalization in regard to choice and diversity in domestic, sexual and kinship relations".
} 


\title{
O feminismo como perspectiva crítica
}

\begin{abstract}
Over coming the silencing of women is an extreme act, a sequence of extreme acts. Breaking our silence means living in existential courage. It means discovering our deep sources, our spring. It means finding our native courage. It means dis-covering our deep sources, our spring. It means finding our native resiliency, springing into life, speech, action (DALY, 1990, p. 21).
\end{abstract}

Uma das primeiras coisas a se destacar sobre a crítica literária feminista é que ela não configura um corpo homogêneo de conceitos e estratégias de leitura, mas sim um amplo conjunto de variadas proposiçóes temáticas, ideológicas e metodológicas a serem aplicadas ao estudo da Literatura. Outra questão importante, que não se pode perder de vista, é que um dos postulados básicos das diferentes vertentes da crítica literária feminista é a impossibilidade de se pensar o texto literário desvinculado do seu contexto de leitura e produçấo, bem como do contexto onde se realiza a sua leitura. A crítica literária feminista se faz interdisciplinar por definição, uma vez que ela não admite a leitura do texto em um modo desvinculado de sua exterioridade e de sua historicidade.

Um dos principais livros a popularizar a crítica feminista dos costumes, no contexto estadunidense, foi The feminine mystique, de Betty Friedan (1963). O livro, que se propunha a entender as origens da onda de frustração pessoal que assolava a geraçáo de jovens mulheres adultas da década de 1950, rapidamente se tornou um best-seller instantâneo que inspirou toda uma geração na luta pelos direitos das mulheres. Ainda que a matriz dos argumentos de Friedan (1963) estivesse assentada nas preocupaçóes das mulheres brancas de classe média e média-alta, o feminismo da segunda onda rapidamente estabeleceu alianças e coalizóes com os protestos contra a guerra do Vietnã e com a luta pelos direitos civis, engrossando as discussóes em torno das relaçóes étnico-raciais nos Estados Unidos. No eixo principal das reivindicaçôes, encontrava-se a luta contra o patriarcado e a resistência ao masculinismo, a crítica às discriminaçóes no campo civil e busca pela igualdade de oportunidades (principalmente no campo econômico e no acesso à educação formal ${ }^{3}$ ).

É também na década de 1960 que algumas jovens professoras universitárias iniciam uma profunda reflexão questionando o sistema

\footnotetext{
${ }^{3}$ Para uma melhor compreensão do contexto da educação feminina na década de 1950, vale observar a representaçáo do ambiente escolar no filme $\mathbf{O}$ sorriso da Monalisa (Dir. Mike Newell, 2003). Um confronto bastante produtivo pode ser realizado cotejando esse filme com Mentes perigosas (Dir. John Smith, 1995), que apresenta os dilemas de uma jovem professora em um college frequentado por latinos e afro-americanos em fins da década de 1990.
} 
educativo, que privilegia os homens brancos; simultaneamente, há a identificação da necessidade de reforma nos currículos universitários, em função da ausência de mulheres escritoras nos currículos de Inglês dos colleges. Emerge também uma primeira crítica à representação misógina das mulheres nas obras canônicas. Inicia-se, no campo dos estudos literários, a adição de uma perspectiva de análise ideológica e política quanto à representação das mulheres nos textos canônicos. Isso se configura como um ataque ao new criticism, modalidade imanentista de análise textual hegemônica nas universidades estadunidenses da época, que ignorava os vínculos dos textos literários com o campo mais amplo da cultura, resultando em uma atividade intelectual que desvinculava as obras do contexto histórico e da vida social.

Não seria exagero mencionar Sexual politics, de Kate Millet (1969), como uma das obras fundacionais da crítica literária feminista. Tributária não apenas de Betty Friedan (1963), mas também de Simone de Beauvoir (1949) e de $\mathbf{O}$ segundo sexo (essa influência, embora possa ser percebida no texto, é recusada por Millet), a autora define politica sexual como a maneira pela qual o sexo dominante (que passa a ser entendido nos mesmos termos de uma classe social dominante) procura manter o controle e o domínio do sexo subordinado; em outras palavras, Millet (1969) sustenta sua teoria da política sexual a partir de uma analogia que aproxima o funcionamento do patriarcado como estrutura política ao da classe dominante (tal como a noçáo é formulada pelo materialismo histórico). Na parte final do livro, Millet (1969) discute romances de Norman Mailler, D. H. Lawrence, Henry Miller e Jean Genet. Ao contrário dos outros escritores discutidos, esse último subverte o regime típico de representaçáo de gênero e sexualidade em sua obra, ao que Millet vai atribuir à homossexualidade assumida de Genet, que o coloca à margem do pacto misógino presente no estamento da produção literária. A autora se coloca na contramão do new criticism, estratégia de leitura hegemônica nas universidades estadunidenses na época, e centra sua argumentação na análise das representaçôes sociais do feminino e do masculino nas obras que constituem seu corpus de pesquisa. Millet (1969), na esteira de Friedan (1963), não compactua com a Psicanálise como modelo de exegese textual, na medida em que a Psicanálise é entendida como uma das estratégias patriarcais e masculinistas que o patriarcado mobiliza em seu esforço para manter as mulheres em uma condição de subordinaçãó .

A recusa da Psicanálise como método interpretativo nos estudos literários feministas é bastante sistemática nas publicaçôes da década de 1960 e inícios da década de 1970. Segundo Patricia Spacks (1976) em The

\footnotetext{
${ }^{4}$ Ver, nesse mesmo caminho, ROGERS, Katharine. The troublesome helpmate: a history of misogyny in literature (1966).
} 
female imagination, apoiada na discussão iniciada por Kate Millet (1969), a Psicanálise é um braço teórico da academia na manutenção da política sexual. Aqui começa a se esboçar o "rompimento" que dá origem a uma tradição anglófona e a uma tradição francófona nos estudos feministas: uma vez que as críticas francesas se utilizaram sistematicamente da Psicanálise, sempre foram vistas com desconfiança pelas feministas inglesas e estadunidenses que se alinhavam às discussóes inaugurais de Millet (1969).

Elaine Showalter (1978) ocupa um papel central na crítica feminista, que até então estava bastante centrada nas representaçóes da mulher em textos literários, mas pouca atençâo dava ao papel da mulher como autora, produtora de capital simbólico e sujeito - não apenas mero objeto - da criação artística e literária. Em seu estudo sobre as escritoras inglesas que publicaram entre 1844 e 1965, intitulado A literature of their own e publicado em 1978, Showalter formula a ideia de três fases da tradição literária de autoria de mulheres: a) a fase feminina (1844-1880), na qual as escritoras imitam os modelos literários vigentes - colocados em circulação pelos escritores homens -, reproduzindo os papéis sociais de gênero; b) a fase feminista (1880-1920), que assinala um período de protesto no qual as mulheres rejeitam as normas vigentes e defendem reformas sociais e direitos iguais em seus projetos literários (tais como o sufrágio universal, o direito ao divórcio e a paridade salarial); e c) a fase da mulher (1920-1965), período no qual surge uma literatura fortemente intimista, caracterizada como "viagem para dentro", quando as escritoras passam a escrever sobre seus processos de autodescoberta.

Embora não se possa transladar o esquema que Showalter (1978) elabora para outros contextos de produção literária, essa divisão tripartite foi articulada por outras críticas em outros contextos literários com resultados interessantes. Showalter (1978) sugere que as mulheres acadêmicas devem abandonar o interesse pelo cânone escrito por homens e se preocupar em estudar/resgatar a tradição literária de autoria feminina. $\mathrm{O}$ que as mulheres estariam escrevendo sobre elas mesmas? Essa proposta, que a autora batiza como ginocrítica (isto é, acrítica literária feita por mulheres, que se ocupam da representaçáo literária de mulheres, em textos escritos por mulheres) é desenvolvida ao longo de um ensaio que é hoje um clássico da crítica literária feminina: Feminist criticism in the wild ness, publicado pela primeira vez na Critical inquiry, em 1981.

É o esforço de Showalter (1981), no sentido de estabelecer uma ginocrítica, bem como os de Ellen Moers (Literary women, 1976) e Josephine Donovan (compiladora do volume coletivo Feminist literary 
theory, de 1975), fundamental para que se inicie, nas universidades estadunidenses, a consolidação de uma das linhas de investigação que até hoje se mantém como uma das mais produtivas no seio da crítica literária feminista: a busca pela escrita de uma tradição literária de autoria feminina, ou seja, por um cânone de obras representativas de uma comunidade feminina, composta de textos escritos por mulheres, sobre mulheres e - mas não necessária ou exclusivamente - para mulheres. Nesse sentido, um dos projetos feministas de maior impacto no campo dos estudos literários tenha sido o extenso trabalho levado a cabo por Sandra Gilbert e Susan Gubar (1979) em The madwoman in the attic: the woman writer and the $\mathbf{1 9}^{\text {th }}$ century literary imagination.

A obra de Gilbert e Gubar (1979) configura-se como um extenso estudo a realizar o mapeamento da tradição literária feminina estadunidense e inglesa do século XIX. As autoras defendem a tese de que as escritoras oitocentistas, ao mesmo tempo em que adotam algumas das convençôes literárias hegemônicas, subvertem algumas das imagens negativas que a literatura de autoria masculina projeta no que diz respeito às mulheres. A parceria entre as duas pesquisadoras iniciou-se na ocasião em que decidiram, juntas, ministrar um seminário sobre escritoras vitorianas. A partir das aulas ministradas sobre as obras de Jane Austen, Mary Shelley, Charlotte e Emily Brontë, George Elliot, Elizabeth B. Browning, Christina Rosseti e Emily Dickinson é que nasceu o projeto de publicarem The madwoman in theattic. Um dos principais eixos explorados pelas autoras é a limitação do script narrativo destinado às personagens femininas na literatura vitoriana: as personagens - em funçáo dos estereótipos consagrados nos textos literários pelos escritores do período - estâo fadadas a se enquadrarem ou na imagem arquetípica da mulher angelical, ou na da mulher monstruosa e diabólica. Explorando o frame teórico desenvolvido por Harold Bloom (1977) em The anxiety of influence, e estendendo suas consequências para as autoras vitorianas, Gilbert e Gubar (1979) chegam a uma importante formulação: a da angústia da autoria. Dado que as mulheres escritoras não dispóem de uma tradição à qual se filiar, nem de uma matriz de modelos literários femininos a serem perpetuados, elas se veem obrigadas a reproduzir as formas literárias vigentes. Todavia, elas o fazem a partir de uma de escrita palimpséstica que produz um texto de dupla voz. Por trás de esquemas narrativos bastante tradicionais e previsíveis do ponto de vista das formas e dos enredos, subtextos subversivos são inseridos, de maneira a materializar o ponto de vista das mulheres escritoras no plano dos conteúdos, mas de uma maneira travestida em que as formas literárias se apresentam de modo convencional. 
The madwoman in the attic tornou-se um marco da crítica literária feminista e uma das inspiraçóes para importantes trabalhos no campo da arqueologia literária feminista (termo utilizado para se referir ao trabalho de resgate de obras literárias de autoria feminina que foram relegadas às margens do cânone justamente em função do gênero de suas autoras $)^{5}$. Gilbert e Gubar $(1989$; 1991; 1994) deram continuidade à sua parceira intelectual com a publicação de No man's land: the place of the women writer in thet wentieth century, onde continuam seu trabalho enveredando-se pelos textos literários de autoria feminina escritos ao longo do século XX. No man's land consumiu uma década e meia de trabalho e de investigação das autoras, sendo publicado em três volumes, identificados pelos subtítulos The war of words (1989), Sex changes (1994) e Letters from the front (1994). O conjunto de três volumes configura-se como a continuação de The madwoman in the attic, enfocando a tradição literária de autoria feminina do século XX. Como ponto forte, busca continuar com o projeto de arqueologia literária realizado com as escritoras do século XIX. Seu ponto fraco, entretanto, é assentar-se em uma lógica à la Harold Bloom, conduzindo a uma exagerada simplificação das noçôes de gênero, indivíduo e sociedade, por enfocar demasiadamente as relaçôes mãe-filha na literatura (tanto no campo da autoria quanto no campo da representação literária).

A partir da década de 1980, simultaneamente à consolidação das pesquisas que se alinham à proposta da ginocrítica de Showalter e do rastreamento de uma tradiçáo literária de autoria feminina proposta por Gilbert e Gubar, consolida-se também uma vertente de investigações que, na interface entre estudos literários e história das religióes, responde pelo nome de mitocrítica feminista. Esse novo campo é designado como aquele que se preocupa com a identificaçáo e a análise dos mitos femininos/feministas na literatura, identificando-se como uma revisão feminista das teorizações feitas por Northop Frye (1957) e Joseph Campbell (1968), entre outros. A pergunta central a nortear esse tipo de investigaçáo pode ser enunciada da seguinte maneira: o que acontece quando a mitologia patriarcal é reescrita a partir da perspectiva da mulher? Uma vez que o mito é definido, tanto em Frye quanto em Campbell, por sua natureza estrutural de caráter estável, quase imutável ao longo da história, faz-se bastante pertinente a formulação

\footnotetext{
${ }^{5}$ Cabe mencionar aqui o projeto de resgate de escritoras brasileiras coordenado por Zahide Muzart. O resultado foi publicado em três alentados volumes por ela organizados, intitulados Escritoras brasileiras do século XIX, publicados pela Editora Mulheres, de Florianópolis, em parceria com a Editora da UNISC, em Santa Cruz do Sul (RS). O primeiro volume foi publicado em 1999, o segundo em 2004 e o terceiro em 2009, totalizando mais de 3200 páginas e mais de 150 escritoras oitocentistas resgatadas do esquecimento pela historiografia literária.
} 
de uma compreensão feminista que vê na busca feminina (ao contrário da busca do herói descrita por Campbell) não a manutenção do esquema mítico, mas sim a violência contra a lógica das estruturas míticas. São dignas de nota nesse campo Carol Christ, Mary Daly, e Maureen Murdock.

A psicoterapeuta junguiana e instrutora de escrita criativa, Maureen Murdock, é responsável por uma releitura feminista da jornada do herói proposta por Joseph Campbell (1968) em A herowith a thousand faces. Em The heroine's journey, Murdock (1990) reelabora a estrutura masculinistado monomitode Campbell, ao se preocupar em descrever a estrutura mítica da busca feminina. Já em A filha do herói, Murdock (1998) centra-se na dinâmica das relações pai-filha, tomando como ponto de partida o anacronismo do mito do herói desenvolvido por Campbell quando se pensar no papel do pai contemporâneo. Ainda que o trabalho de Murdock esteja muito mais voltado para - e comprometido com - as demandas da prática analítica de consultório, e não para a formulação de modelos de análise textual, ela realiza uma inegável contribuição ao demonstrar o quanto o célebre modelo textual de Campbell (1968) e a noção de monomito (formulada no estudo da mitologia comparada e frequentemente transladado para a crítica literária) ${ }^{6}$ está calcado em uma lógica masculinista. É sintomática a conversa que Murdock teve com Campbell acerca do monomito, e que ela relata nas primeiras páginas de

\title{
The heroine's journey:
}

\begin{abstract}
Meu desejo de entender de que modo a jornada da heroína relacionava-se com a jornada do herói me fez conversar com Joseph Campbell, em 1981. Eu já desconfiava que os estágios da jornada da heroína incorporava, alguns aspectos da jornada do herói, mas sentia que o fodo da evolução espiritual feminina era o de suturara divisão interna entre a mulher e sua natureza feminina. Eu queria ouvir o que Campbell pensava sobre isso. Fiquei estupefata quando ele respondeu-me que as mulheres não necessitavam fazer a jornada. "Em toda a tradição mitológica, a mulher é. Tudo o que ela tem de fazer é conscientizar-se que está no lugar onde as pessoas estão tentando chegar. Quando uma mulher percebe esta característica maravilhosa, ela náo fica mais confusa com a noçấo de ser um simulacro de macho" [disse Campbell] (MURDOCK, 1990, p. 26, tradução nossa).
\end{abstract}

${ }^{6} \mathrm{O}$ monomito, também chamado de "jornada do herói”, é um termo cunhado por Joseph Campbell para referir-se à estrutura cíclica reincidente nas jornadas dos grandes heróis míticos. O termo, utilizado pelo autor pela primeira vez em A herowith a thousand faces, foi ressignificado por Campbell, mas já havia sido utilizado por James Joyce em Finnegan's Wake (1839). 
Carol Christ e Mary Daly são dois importantes nomes da teologia feminista. Paratal teoria, a capacidade para a liberdade é fundamental para configurar uma experiência do sagrado. Logo, o trabalho feminista sobre o mito não é mera des-mitificação, mas também re-mitificação: busca de novas modalidades de vivenciar o sagrado. É a partir daí que se pode começar a entender algumas das buscas feministas, no sentido de recuperar mitologias pré-patriarcais, tais como o culto às grandes deusas no Egito, no Oriente Próximo e nas religióes africanas. Tanto Christ quanto Daly ${ }^{7}$ estão preocupadas com a reformulação das alternativas para as mulheres efetivarem sua busca espiritual, sua evolução pessoal, seu caminho rumo à iluminação, ou qualquer outro nome que sequeira dar a essa jornada rumo ao autoconhecimento. Está presente na obra das duas autoras a importante questáo dos limites da linguagem e da necessidade de se criar uma nova linguagem - ou, pelo menos, de se deformar a linguagem com vistas a expressar as especificidades das experiências da Busca feminina. Também está presente, na obra das duas autoras, um projeto comum de construção coletiva de histórias devida e de experiências compartilhadas, em especial nas suas respectivas práticas docentes.

Mary Daly foi uma das mais importantes teólogas feministas nos EUA, identificando-se com o feminismo lésbico radical. Em Gyn/Ecology, uma das propostas radicais de Daly (1978) é a da criação de uma cultura feminina, de novos modos de pensar e de viver em comunidade, avessos à religiáo do patriarcado. Nesse sentido, sua proposta encontra-se com a de Carol Christ no que diz respeito à proposiçáo do uso da subversão da linguagem e da ressignificaçáo e do compartilhamento das histórias pessoais das mulheres como modalidade de resistência. As duas autoras fornecem subsídios extremamente importantes para que se possa ir das preocupaçóes teológicas ao pensamento mítico, e do trabalho com as narrativas míticas ao trabalho crítico com as narrativas literárias:

If we look at the term text in contrast to textile, we see that this represents the other side of the schizoid condensation of weaving/spinning. "Texts" are

\footnotetext{
${ }^{7}$ Pelo menos duas questôes controversas envolveram o trabalho de Mary Daly: sua recusa em aceitar homens nas suas classes avançadas no Boston College (aceitava homens em seus cursos introdutórios - graduação - mas passou a recusar alunos em seus cursos avançados, o the rendeu uma aposentadoria forçada em 1999), argumentando que eles intimidavam o diálogo e a discussão entre mulheres, e suas posiçóes radicais contra a transexualidade (que ela via como um movimento do patriarcado para usurpar a feminilidade das mulheres). Ela descreve o patriarcado como a religião da dominação das mulheres. Algum tempo após a publicação de Gyn/Ecology, Daly afasta-se da Teologia, concentrando seu trabalho em Filosofia (ética feminista).
} 
the kingdom of males; they are the realm of the reified word, of condensed spirit. In patriarchal tradition, sewing and spinning are for girls; books are for boys (DALY, 1978 [1990], p. 5).

Gyn/Ecology, de Mary Daly (1978), culmina por configurar-se como nada menos do que uma recusa deliberada à manutenção das mitologias masculinistas e à respectiva linguagem que codifica essas mitologias. Para Daly (1978), o estudo, a investigação e a reformulação das narrativas míticas se faz fundamental não apenas para desvelar a ideologia patriarcal que as sustenta, mas também para possibilitar a emersão de mitologias feministas e para instigar novos enfoques culturais através da dessacralização - quando não da própria inversão - dos mitos ${ }^{9}$.

\title{
Consideraçóes finais: o lugar da leitora
}

\begin{abstract}
Trazer a literatura para a realidade em que vivemos, mostrar aos nossos alunos a importância da reflexão crítica como porta de acesso e discernimento entre velhos e novos conhecimentos a partir dos quais podemos forjar realidades possíveis que venham ao encontro do nosso desejo de identidades humanas, plenas e soberanas, no contexto de uma sociedade mais justa, igualitária e solidária, é a demanda que se impóe se quisermos ser os educadores e intelectuais comprometidos com o nosso tempo (SCHMIDT, 2006, p. 110).
\end{abstract}

Ainda que as teorias feministas também sejam, como as demais teorias literárias, teorias de interpretação, há pontos importantes nos quais as teorias feministas diferem das demais teorias que pautam a atividade da crítica literária. Em primeiro lugar, elas implicam um olhar crítico sobre os próprios postulados básicos dos processos de intepretação: por que se interpreta de uma maneira e não de outra em um determinado momento histórico? Por que se interpreta de diferentes maneiras em diferentes períodos históricos? Em segundo lugar, as teorias feministas supóem a existência de uma relação complexa entre os textos literários e o contexto sociocultural, histórico e geográfico em que esses mesmos textos foram produzidos. Essa relação, entretanto, nunca é transparente, tampouco se dá termo-a-termo, uma

\footnotetext{
${ }^{8}$ A primeira edição do livro é de 1978 . Cito-o, entretanto, tomando como base a segunda edição, de 1990.

9 "Feminists have been creating a rich culture, creating new forms of writing, singing, celebrating, cerebrating, searching. We have been developing new strategies and tactics for organizing - for economic, physical, and psychological survival. To do this, we have had to go deep inside our Selves" (DALY, 1990, p. xlix).
} 
vez que a literatura não reflete o mundo, mas o representa. Mesmo a mais inocente das análises imanentistas, centrada apenas em aspectos formais e textuais favorece e reitera uma concepção particular de Literatura que, por sua vez, fomenta uma determinada concepção de mundo. Em terceiro lugar, as relaçôes que se estabelecem entre diferentes textos literários, bem como as relaçôes que se estabelecem entre textos literários e outros discursos que entre eles circulam (e que se encontram à disposição de um determinado público ou comunidade interpretativa) são necessariamente políticas, posto que implicam relaçóes de saber/poder. Finalmente, as teorias feministas pressupóem um lugar de destaque dado a uma questão fundamental não privilegiada pelas outras teorias: o lugar da mulher como produtora, consumidora e objeto representado nos textos literários.

Entre as preocupaçóes da crítica literária feminista, vale retomar três pontos fundamentais: a) preocupação com a história literária (em especial aquela escrita sob o ponto de vista dos homens), o apagamento das mulheres autoras dessa história literária, e a manutenção de uma mitologia literária misógina (que toma as mulheres exclusivamente como objeto da representação); b) o lugar da leitora e da leitura nos estudos literários, e c) a ginocritica (mulheres que estudam textos sobre mulheres, escritos por mulheres). Se é verdade que as mulheres, como leitoras, releem a tradição literária sob novas lentes, as mulheres, como escritoras, reescrevem, subvertem e reelaboram a tradição literária.

Após esse breve balanço das origens, que não se pretende mais do que um olhar panorâmico sobre alguns dos textos fundamentais da crítica literária feminista, colocando-os sob escrutínio, torna-se evidente que se pode definir a crítica literária feminista pode ser vista como uma modalidade de prática política, na medida em que vincula reflexão teórica e ativismo, com vistas a alcançar a transformação da própria subjetividade. Essa transformação é o primeiro passo em direção a uma mudança social mais ampla, tanto no campo cultural quanto no campo político.

É de suma importância não esquecer que, no âmago da questão, não se encontra apenas o fato de se interpretar as obras literárias de formas diferentes, colocando o texto literário em confronto com o mundo mais amplo dos esquemas culturais, das narrativas míticas e das representaçóes sociais, mas também de mudar o mundo, por mais utópica que essa afirmação possa parecer. Não se pode deixar de lado a atividade de leitura, pois é exatamente na leitura que a Literatura exerce seu potencial de praxis e atua no mundo de forma a operar sobre os seus leitores. 


\section{Referências}

BLOOM, Harold. The anxiety of influence. 2nd. ed. Oxford: Oxford University Press, 1997.

BUTLER, Judith. Gender trouble. London: Routledge, 1990.

. Bodies that matter. London: Routledge, 1993.

CAMPBELL, Joseph. The hero with a thousand faces. Princeton: Princeton UP, 1968.

CAVENDISH, Margareth. The convent of pleasure. London: Printed by A. Maxwell, 1668.

CHODOROW, Nancy. The reproduction of mothering: psychoanalysis and the sociology of gender. Berkeley: U of California P, 1978.

CHRIST, Carol. Diving deep and surfacing: women writers on spiritual quest. Boston: Beacon Press, 1980.

Diving deep and surfacing:women writers on spiritual quest.3. ed. Boston: Beacon Press, 1995.

DALY, Mary. Gyn/Ecology: the metaethics of radical feminism. Boston: Beacon Press, 1978.

. Gyn/Ecology. 2nd. ed. Boston: Beacon Press, 1990.

DONOVAN, Josephine (Ed.). Feminist literary criticism: explorations in theory. Lexington: U of Kentucky P, 1975.

FALUDI, Susan. Backlash: the undeclared war against American women. New York: Crown, 1991.

FLAX, Jane. Thinking fragments: psychoanalysis, feminism, and postmodernism in the contemporary West. Berkeley: University of California Press, 1990.

FRIEDAN, Betty. The feminine mystique. New York: Dell, 1963.

. Mística feminina: o livro que inspirou a revolta das mulheres americanas. Rio de Janeiro: Vozes, 1971.

FRYE, Northop. Anatomy of criticism. Princeton: Princeton UP, 1957. 
GILBERT, Sandra M.;GUBAR, Susan. The madwoman in the attic: the woman writer and the $19^{\text {th }}$ century literary imagination. New Heaven: Yale UP, 1979.

; GUBAR, Susan. No man's land: the place of the women writer in the twentieth century. [Volume 1: The war of the words]. New Heaven: Yale UP, 1989.

; GUBAR, Susan. No man's land: the place of the women writer in the twentieth century. [Volume 2: Sexchanges]. New Heaven: Yale UP, 1991.

; GUBAR, Susan. No man's land: the place of the women writer in the twentieth century. [Volume 3: Letters from the front].New Heaven: Yale UP, 1994.

HANISCH, Carol. The personal is political. 1969. Disponível em: <http:// www.carolhanisch.org/CHwritings/PIP.html>. Acesso em: 10 mar. 2017.

HOOKS, bell. Teaching to transgress. London: Routledge, 1994.

LEAR, Marta W. The second feminist wave. The New York Times Magazine, 10 March 1968.

LAURETIS, Teresa de. Technologies of gender: essays on theory, film, and fiction. Bloomington: Indiana University Press, 1987.

MILLET, Kate. Sexual politics. New York: Doubleday, 1969.

MACAULAY, Catherine. Letters on Education with observations on religious and metaphysical subjects. London: C. Dilly, 1790.

MCROBBIE, A. Post-feminism and popular culture. Feminist Media Studies, v. 4, n. 3, p. 255-264, 2004.

MOERS, Ellen. Literary women: the great writers. New York: Doubleday, 1976.

MURDOCK, Maureen. The heroine's journey. Boston: Shambala Publications, 1990.

A filha do herói: mito, história e amor paterno. Trad. Sâmia Rios. São Paulo: Summus, 1998.

PIZAN, Christine de. A cidade das damas. Trad. Luciana Eleonora de Freitas Calado Deplangne. Florianópolis: Mulheres, [1405] 2012. 
ROGERS, Katharine. The troublesome helpmate: a history of misogyny in literature.Seattle: U of Washington P, 1966.

SPACKS, Patricia Meyer. The female imagination. London: Allen and Unwin, 1976.

SCHMIDT, Rita Terezinha. O fim da inocência: Medusas de ontem e de hoje. Signo, UNISC - Santa Cruz do Sul, Ed. Especial, p. 95-112, 2006.

SHOWALTER, Elaine. Feminist criticism in the wildness. Critical Inquiry, v. 8, n. 2, Writing and Sexual Difference, p. 179-205, Winter, 1981.

1978.

A literature of their own. Princeton: Princeton University Press,

SMITH, Barbara. The truth that never hurts: writings on race, gender and freedom. 2nd. ed. New Brunswick: Rutgers University Press, 1998.

Anselmo Peres Alós <anselmoperesalos@gmail.com> Bárbara Loureiro Andreta <barbaraandr@hotmail.com>

Recebido: 29/03/2017 Aceito: $24 / 07 / 2017$ 